\title{
Size Effects on Process Performance and Product Quality in Progressive Microforming of Shafted Gears Revealed by Experiment and Numerical Modeling
}

\section{Jun-Yuan Zheng}

Department of Mechanical Engineering, The Hong Kong Polytechnic University https://orcid.org/00000001-7711-5285

Hui Liu

Department of Mechanical Engineering, The Hong Kong Polytechnic University

M.W. Fu ( $\nabla$ mmmwfu@polyu.edu.hk)

Department of Mechanical Engineering, The Hong Kong Polytechnic University

\section{Research Article}

Keywords: Microforming, microprocess performance, microforming quality, size effect affected deformation behavior, die design optimization

Posted Date: February 28th, 2022

DOI: https://doi.org/10.21203/rs.3.rs-1403250/v1

License: (a) (i) This work is licensed under a Creative Commons Attribution 4.0 International License.

Read Full License 


\title{
Size Effects on Process Performance and Product Quality in Progressive Microforming of Shafted Gears Revealed by Experiment and Numerical Modeling
}

\author{
Jun-Yuan Zheng, Hui Liu, and M. W. Fu* \\ Department of Mechanical Engineering, The Hong Kong Polytechnic University, \\ Hung Hom, Kowloon, Hong Kong SAR of China \\ *mmmwfu@polyu.edu.hk
}

\begin{abstract}
\end{abstract}
As one of the indispensable actuating components in micro-systems, the shafted microgear is in great production demand. Microforming is a manufacturing process to produce microgears to meet the needs. Due to the small geometrical size, there are uncertain process performance and product quality issues in this production process. In this study, the shafted microgears were fabricated in two different scaling factors with four grain sizes using a progressively extrusion-blanking method. To explore the unknown of the process, grain-based modeling was proposed and employed to simulate the entire forming process. The results show that when the grains are large, the anisotropy of single grains has an obvious size effect on the forming behavior and process performance, the produced geometries and surface quality are worsened, and the deformation load is decreased. Five deformation zones were identified in the microstructures with different hardness and distributions of stress and strain. The simulation by using the proposed model successfully predicted the formation of zones and revealed the inhomogeneous deformation in the forming process. The undesirable geometries of microgears including material unfilling, burr and inclination were 
observed on the shaft and teeth of gear, and the inclination size is increased obviously with grain size. To avoid the formation of inclination and material unfilling, the punch was redesigned, and a die insert was added to constraint the bottom surface of the gear teeth. The new products had then the better forming quality.

\section{Article highlights}

1. Shafted microgears were fabricated through progressive microforming, and size effects on the process and product were investigated.

2. Simulations using the proposed size-dependent model can reflect the inhomogeneous deformation in microforming.

3. The forming dies are optimized to improve the material unfilling and inclination on the formed microgears.

Keywords: Microforming, microprocess performance, microforming quality, size effect affected deformation behavior, die design optimization

\section{Introduction}

In recent years, the demand for various microparts in many industrial fields is increasing continuously [1,2]. Micromanufacturing technologies such as additive manufacturing [3], ion beam etching [4], micro-discharge machining [5], laser processing [6], ultra-precision machining [7] play great roles in satisfying the different manufacturing demands, and among them, microforming [8] is a wide-applied technology, which has high productivity and great net-shape or near-net-shape formation. However, the development of microforming is limited by the material feeding, handling, transporting and positioning [9]. Progressive microforming thus 
emerged aiming to address the above problems, which consists of progressive tooling and several forming operations with a given sequence [10]. Moreover, with scaling down to microscale, the material deformation is different from that in macroscale due to size effect. Many researchers have investigated how size effect affects microforming processes. Zheng et al. [11-13] developed a progressive forming system including blanking and extrusion operations, and they fabricated pin-shaped plunger parts, plugshaped parts and flanged parts to investigate the deformation load, formation accuracy and surface problem to analyze the size effect. Chan et al. [14] studied grain size effect in micro-compression experiments, and the results indicated that the properties of individual grains play great roles and would cause inhomogeneous deformation with the decreasing number of grains. Chan et al. [15] investigated microembossing process of microchannels and revealed the size effect on surface roughening and local deformation behaviors. Wang et al. [16] studied the fracture behaviors of materials in microscale, and they found the deformation behavior is influenced by the grain size effect and stress condition significantly.

Nowadays, micro-electro-mechanical system (MEMS) has been widely industrialized, which increases the demand for environmentally friendly and low-cost manufacturing of various microparts. As a type of indispensable actuating component in MEMS, the microgear is broadly applied for changing the speed, torque, direction and form of motion. The manufacturing of microgears has been tried in different ways by many investigators including powder metallurgy, milling technology, laser cutting, and microforming $[17,18]$. Debin et al. [19] proposed a hybrid process combining the isothermal closed forging process to manufacture miniature double gears. Tay et al. [20] successfully fabricated microgears through micro powder injection process by using 316L stainless steel powder. Liu et al. [21] investigated the mouldability of various zirconia microgears based on different binder systems, and the forming results indicated 
that the gears with a diameter below $0.5 \mathrm{~mm}$ were difficult to be molded due to sticking. Dong et al. [22] performed extrusion to fabricate microgears by using the 7075 aluminum alloy, and they found that good lubrication conditions and high temperatures make the extrusion load decline obviously and the gear surface quality better. Chen et al. [18] investigated the grain size effect during the forging process of microgears and found that the material with large grains has a poor flow condition on the die substrate and a small maximum deformation load. Li et al. [23] developed a novel laser dynamic flexible stamping process using shockwaves as the punch, which can solve the problem of die alignment better compared with the traditional micro-stamping process. Vollertsen et al. [24] developed a method to form the microgear on the thickness direction of copper sheet, but the surface quality of the formed gear was poor due to the twisting operation at the end of production. Wang et al. [25] presented a process of microwire electrical discharge machining to achieve the precise fabrication of microgears, and the results indicated that the formation accuracy was high and the surface roughness was low.

Although various manufacturing technologies of microgears have been performed in the above literature review, there is still a lack of research on shafted gears by progressive microforming method using sheet metals, and the research on size effects in microforming processes is limited. In this research, a progressively extrusionblanking microforming system was developed to fabricate shaft gears in two scales with various grain sizes to investigate size effect. The product quality and forming performance were analyzed through experiments and simulations using a proposed model from the aspects of deformation load, microstructures, distribution of stress and strain, undesirable geometry, microhardness, and surface quality. The proposed sizedependent constitutive model predicted precisely and reflected the inhomogeneous deformation in microscale. In addition, the causes of undesirable geometries were 
analyzed, and the forming system was thus improved to obtain better product quality.

\section{Material and experiment}

\subsection{Testing material}

H75 brass ( $75 \mathrm{wt} \%$ copper and $25 \mathrm{wt} \%$ zinc) was chosen as the testing material in this study. The brass sheets with thicknesses of 0.6 and $1.0 \mathrm{~mm}$ were annealed with different temperatures viz., $450^{\circ} \mathrm{C}, 550^{\circ} \mathrm{C}, 600^{\circ} \mathrm{C}$ and $700^{\circ} \mathrm{C}$ for 1 hour to obtain various grain sizes. The argon gas was filled in the furnace to avoid oxidation during annealing. To observe the microstructure of the cross-section along the thickness direction, the brass sheets were polished and etched in a solution of $5 \mathrm{~g}$ Ferric chloride, $15 \mathrm{ml}$ Hydrogen chloride, and $85 \mathrm{ml}$ water for about 15 seconds. The microstructure photos with the annealing temperatures and their corresponding grain sizes are shown in Fig. 1, which were captured by an optical microscope, Epiphot 200 Nikon. The grain sizes were measured according to the standard of ASTM E112. Moreover, the mechanical properties of brass sheets were obtained by conducting uniaxial tensile tests using the dog-bone-shape specimens with thicknesses of 1.0 and $0.6 \mathrm{~mm}$ under various grain sizes, and their dimension is shown in Fig. 2 (c). Two white points were marked on specific positions of specimen used to measure the elongation until fracture. The speed of crosshead is $1.5 \mathrm{~mm} / \mathrm{min}$ with the strain rate of $0.001 \mathrm{~s}^{-1}$ under a quasi-static condition. Three repeated tests were conducted for the same thickness and approximate grain size. The stress-strain curves are shown in Fig. 2 (d). It is revealed that the true stress decreases obviously with the growth of grain size since the grain boundary strengthening effect is weakened as the proportion of grain boundary declines. 


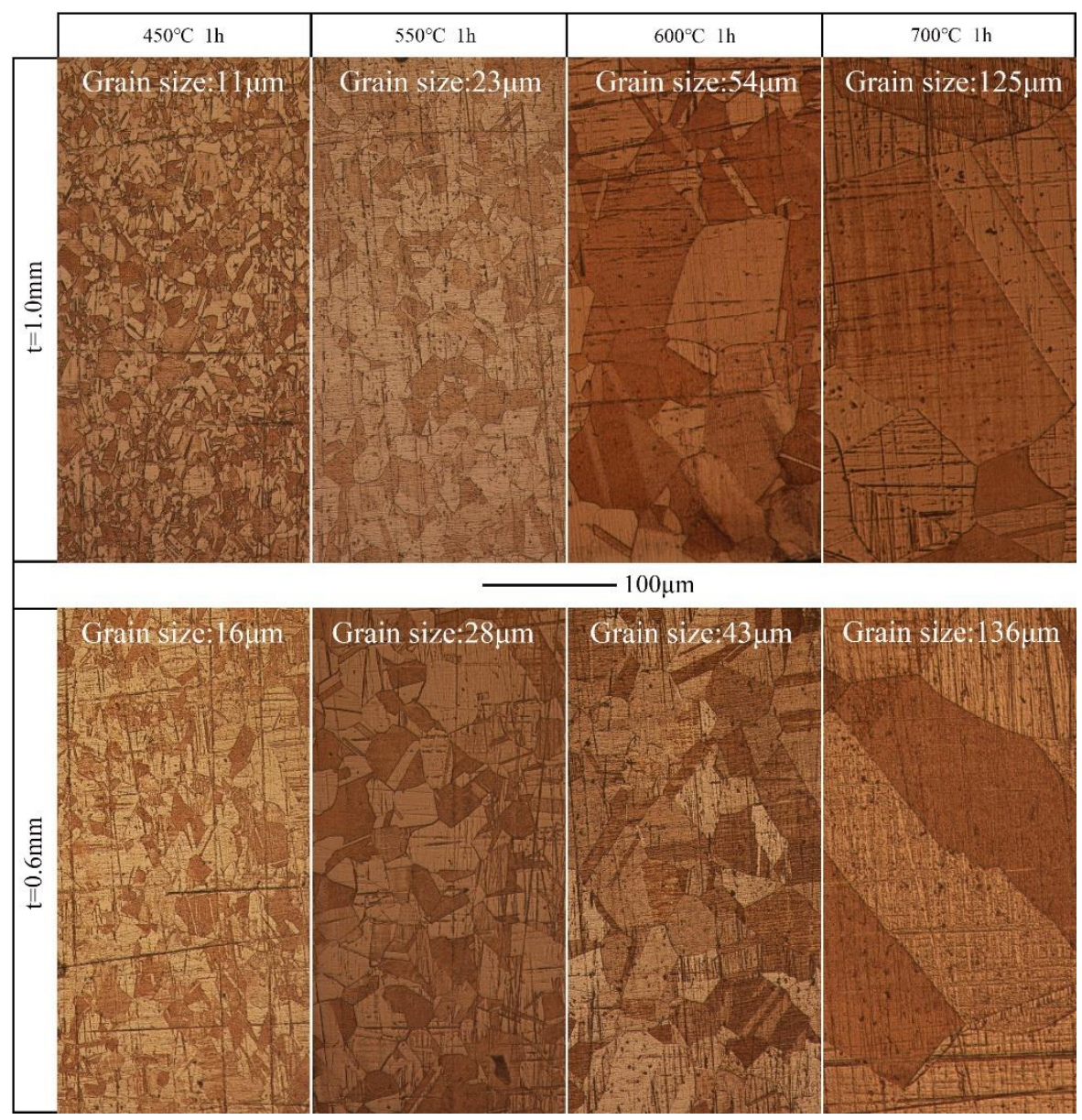

Fig. 1 The microstructures of the annealed brass sheets. 

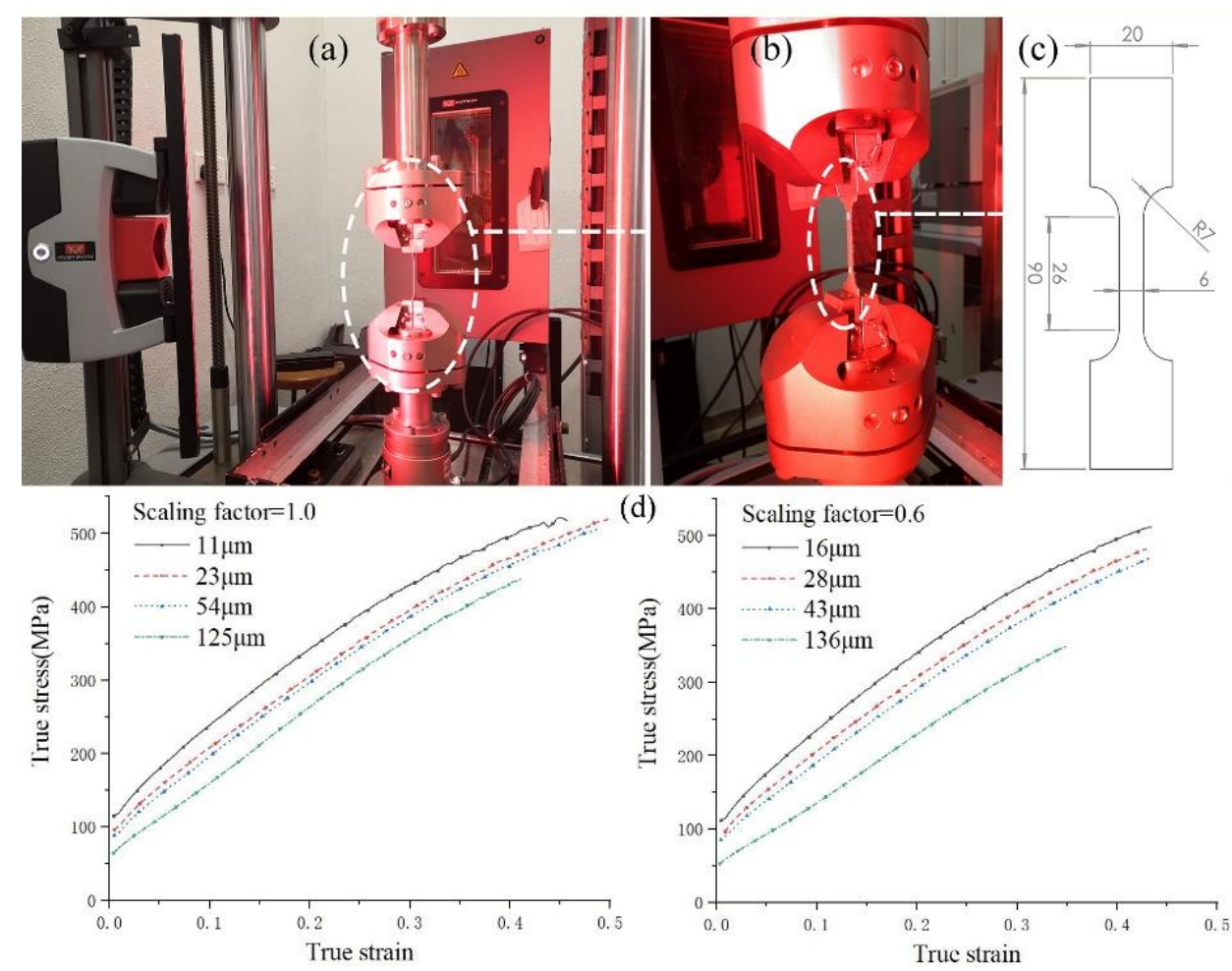

Fig. 2 (a, b) The MTS uniaxial tensile machine. (c) The dog-bone-shape specimen used in the tensile test and its dimensions. (d) The stress-strain relation of the testing materials.

\subsection{Microforming system and microgear}

The design and dimensions of the microgear are illustrated in Fig. 3 (b, c), which has six gear teeth and two shafts on both sides. The scaling factors refer to the ratio of the brass sheet thickness to $1 \mathrm{~mm}$ to distinguish the two sizes in the following explanation, which are 1 and 0.6 , respectively. For microforming, it is important to consider the positioning between material and die, the transportation of material, and the ejection of final parts [9]. The microforming system was designed concerning the above factors and drawn by CAD software SolidWorks, as shown in Fig. 3 (a). This system adopts two progressive operations namely extrusion and blanking to form the shafted microgear. At the beginning, the shafts are simultaneously formed by extrusion, then the brass sheet is moved forward, and positioned by the preformed shaft. Next, 
blanking is performed to form the teeth of microgear. Fig. 4 illustrates the forming process and the final part. Machine oil was used on the interface between brass sheet and die to reduce the interfacial frictional effect. The stroke speed was fixed at 0.005 $\mathrm{mm} / \mathrm{s}$ in the whole process to make the strain rate effect neglectable. The whole microforming process was done by an MTS testing machine with a $50 \mathrm{kN}$-capacity load cell.
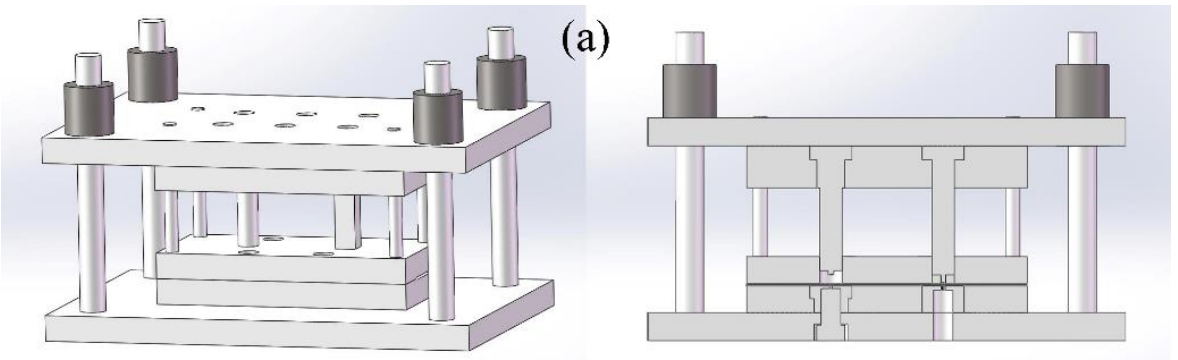

(b)

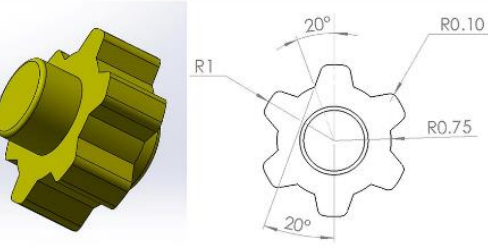

(c)

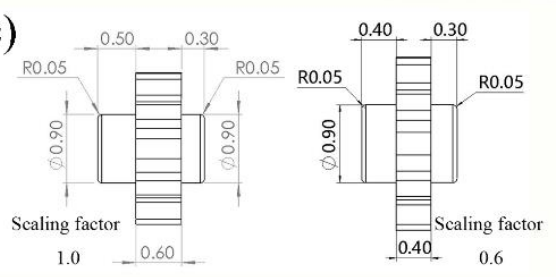

Fig. 3 (a) Microforming system. (b) Design of microgear. (c) Dimensions of microgear in two scale factors.

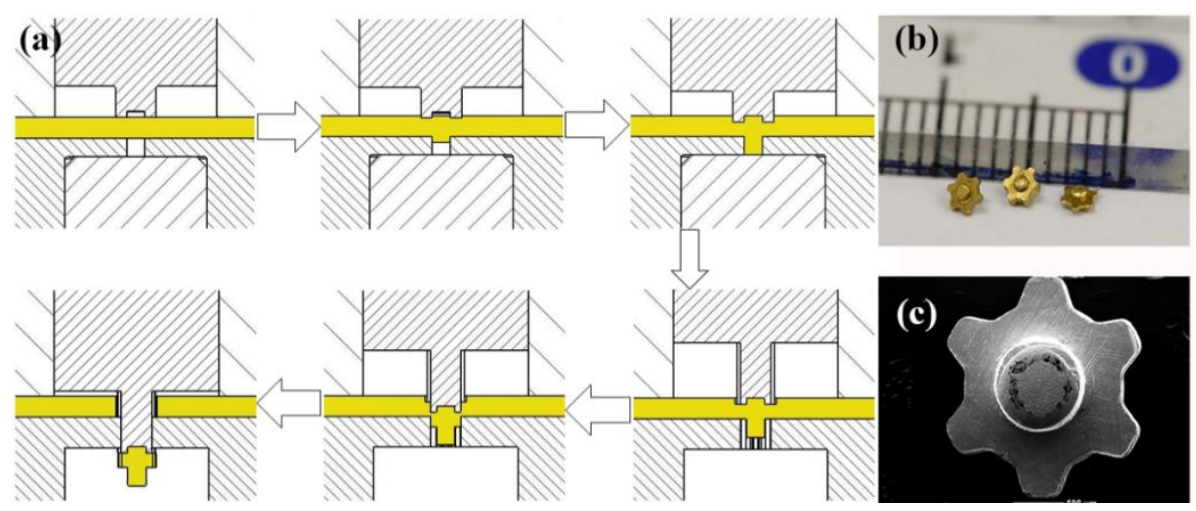

Fig. 4 (a) The forming process and $(b, c)$ the formed gears. 


\section{Size-dependent material constitutive modeling}

Knowing the mechanical properties of the testing material is important to predict the deformation behaviors in the microforming process. In this section, a sizedependent constitutive model considering the surface layer model (SLM) and the HallPetch (H-P) relationship is developed based on the tested results.

\subsection{Theoretical model}

SLM represents size effects (SEs) of materials by assuming the unique properties of surface grain (SG) and inner grain (IG). The IGs of material are considered as polycrystal, where H-P relationship indicates that the material is strengthened with the increase of grain boundaries. The SGs have fewer constraints from adjacent grains compared with the IGs, thus the grain boundary strengthening effect could be neglected. The flow stress $\sigma(\varepsilon)$ of material can be designated in the following:

$$
\left\{\begin{array}{c}
\sigma(\varepsilon)=f_{I G} \sigma_{I G}(\varepsilon)+f_{S G} \sigma_{S G}(\varepsilon) \\
\sigma_{I G}(\varepsilon)=\sigma_{0}(\varepsilon)+\frac{k(\varepsilon)}{\sqrt{d}} \\
\sigma_{S G}(\varepsilon)=\sigma_{0}(\varepsilon)
\end{array}\right.
$$

where $f_{I G}, f_{S G}, \sigma_{I G}$, and $\sigma_{S G}$ are the fractions and flow stresses of SGs and IGs, respectively, and $\sigma_{0}(\varepsilon)$ and $k(\varepsilon)$ are constants at a given strain. As shown in Eq. (1), $\sigma_{I G}(\varepsilon)$ can be divided into two parts, one is independent of grain size $(d)$ and the other one is grain-size dependent. $\sigma_{0}(\varepsilon)$ can be regarded as the flow stress of grain interior, and $k(\varepsilon) / \sqrt{d}$ can be considered as the strength contributed by additional resistance to dislocation motion due to grain boundaries.

As shown in Fig. 5, a sheet specimen is assumed to have only two layers of SGs since the width and length are much larger than the thickness, thus $f_{S G}$ and $f_{I G}$ can 
be designated as $d / t$ and $1-d / t$, respectively. Therefore, Eq. (1) can be expressed as follows:

$$
\sigma(\varepsilon)=\left(1-\frac{d}{t}\right)\left(\sigma_{0}(\varepsilon)+\frac{k(\varepsilon)}{\sqrt{d}}\right)+\frac{d}{t} \cdot \sigma_{0}(\varepsilon)=\sigma_{0}(\varepsilon)+\frac{t-d}{t \sqrt{d}} \cdot k(\varepsilon)
$$

In the above equation, the flow stress has two partitions, where the former is sizeindependent, and the latter depends on the grain size $(d)$ and thickness $(t)$. A factor $N$ is introduced to describe the interactive SEs of $d$ and $t$.

$$
\sigma(\varepsilon, N)=\underbrace{\sigma_{0}(\varepsilon)}_{\text {size-independent }}+\underbrace{N k(\varepsilon)}_{\text {size-dependent }}
$$

where $N=\frac{t-d}{t \sqrt{d}}$ is the size factor, which is related to $d$ and $t$.

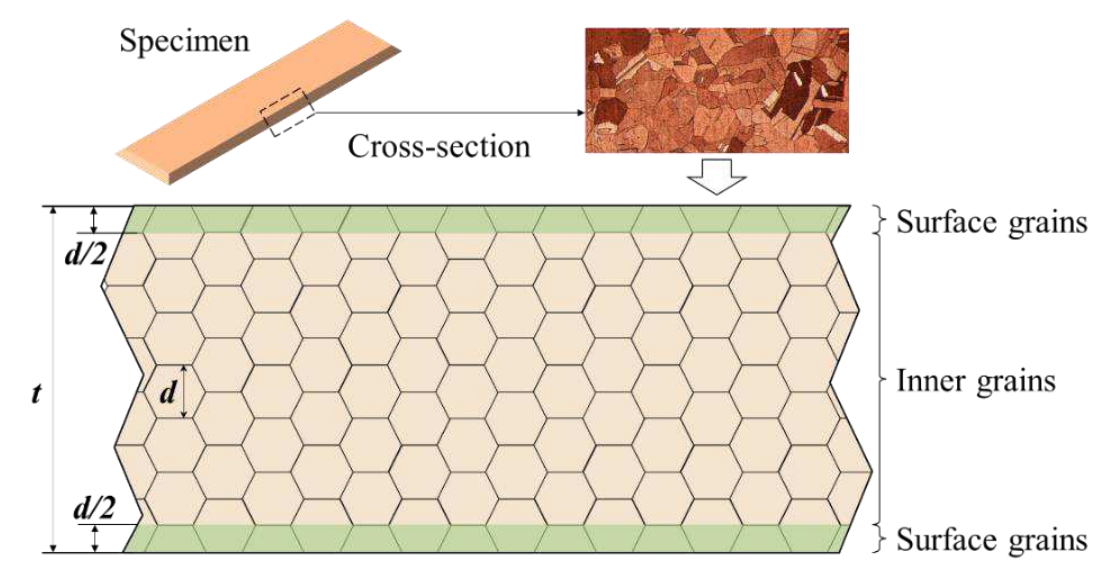

Fig. 5 The grain distribution in the cross-section of a sheet specimen, consisting of surface grains (SGs) and inner grains (IGs).

\subsection{Experimental data fitting}

$\sigma_{0}(\varepsilon)$ and $k(\varepsilon)$ can be obtained by the data fitting method from $\sigma(\varepsilon)-N$ linear relation in power-law form with different $d$ and $t$, as shown in Fig. 6 (a). Then the intercept and slope of the linear relation, which are $\sigma_{0}(\varepsilon)$ and $k(\varepsilon)$ respectively, can be obtained and fitted in power-law form, as shown in Fig. 6 (b) and (c). In this 
study, two thicknesses with four grain sizes in each of the brass sheets were selected, and their related $N$ values are listed in Table 1. Finally, the following equations are obtained to describe the flow stress curves:

$$
\left\{\begin{array}{c}
\sigma_{0}(\varepsilon)=33+814 \varepsilon^{0.9} \\
k(\varepsilon)=16 \varepsilon^{0.1}
\end{array}\right.
$$

By taking Eq. (4) into Eq. (3), the fitted model and the experimental data to describe the flow stress of brass are illustrated in Fig. 7. It can be found that the flow stress increases with the decrease of grain size due to the grain boundary strengthening. The proposed model can reflect this tendency and is consistent with experimental results.

Table 1 The $N$-values with different thicknesses and grain sizes.

\begin{tabular}{c|cccc|cccc}
\hline Thickness $/ \mathrm{mm}$ & \multicolumn{4}{|c|}{0.6} & \multicolumn{5}{c}{1.0} \\
\hline Grain size $/ \mu \mathrm{m}$ & 16 & 28 & 43 & 136 & 11 & 23 & 54 & 125 \\
\hline$N$ & 7.6949 & 5.6973 & 4.4768 & 2.0970 & 9.4297 & 6.4421 & 4.0709 & 2.4749 \\
\hline
\end{tabular}



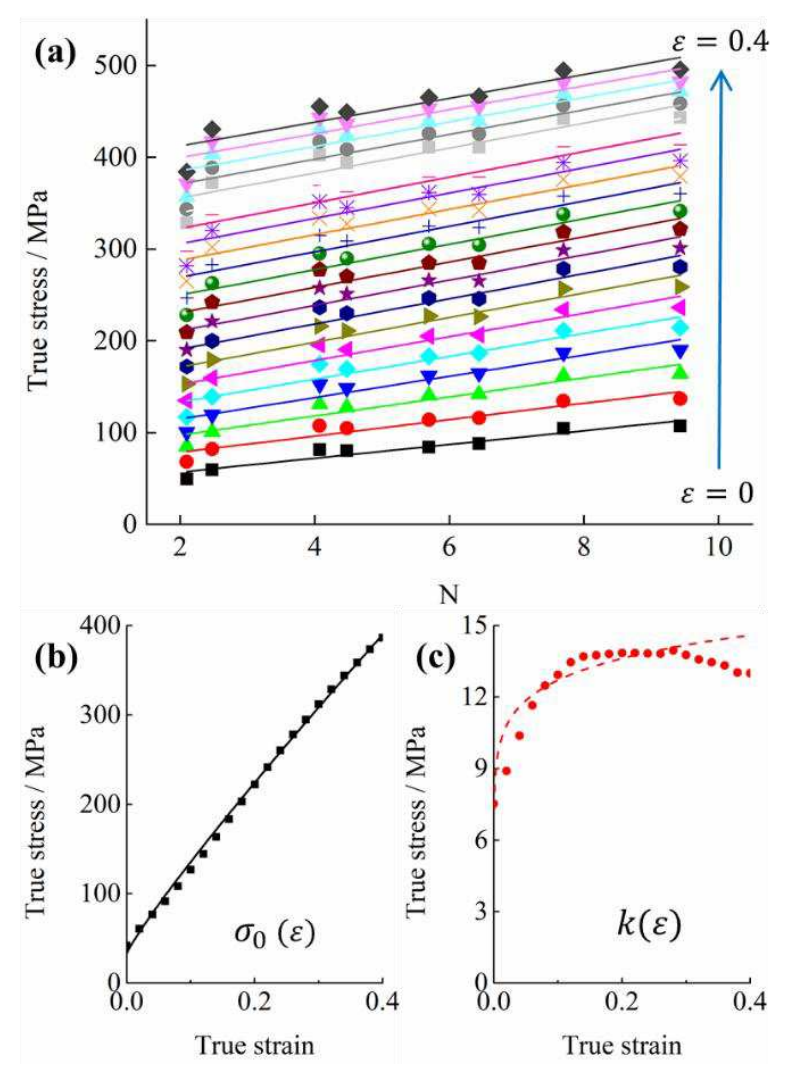

Fig. 6 Experimental results from uniaxial tensile tests of brass. (a) Linear fitting of flow stress $(\sigma)$ - size factor $(N)$ at a given strain $(\varepsilon)$ in the range of 0 to 0.4 . The (b) intercept $\sigma_{0}(\varepsilon)$ and (c) slope $k(\varepsilon)$ of the fitted linear lines and their fitted model in power-law shape. (The blocks represent the experimental data, and the lines and curves represent the fitted equations.) 

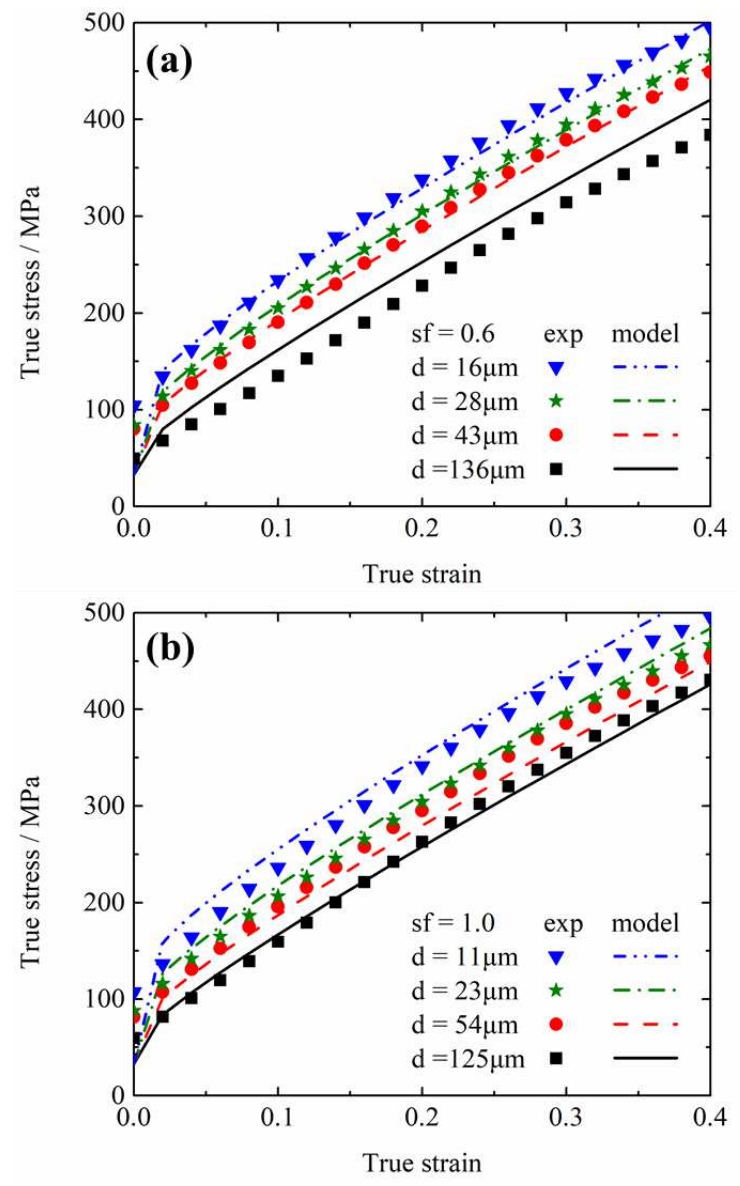

Fig. 7 The stress-strain curves of the fitted model and experimental data with different grain sizes of the brass sheets in the thickness of (a) $0.6 \mathrm{~mm}$ and (b) $1.0 \mathrm{~mm}$.

\subsection{Effect of grain orientation}

The flow stress contributed by grain interior, $\sigma_{0}(\varepsilon)$, can be written as follows in accordance with single-crystal theory and Schmid law [26]:

$$
\sigma_{0}(\varepsilon)=\frac{\tau_{R}(\varepsilon)}{\cos \varphi \cos \lambda}=m \tau_{R}(\varepsilon) \quad(m \geq 2)
$$

where $\tau_{R}(\varepsilon)$ is the critical resolve shear stress (CRSS), $\varphi$ is the angle between the normal stress and the normal direction of the slip plane, and $\lambda$ is the angle between the normal stress and the slip direction. $m$ is the orientation factor (Schmid factor) for the slip system, and ranges between 2 and 3.674 for face-centered-cubic (FCC) lattice with 
the mean value of 3.06 in the Taylor model [27]. Taking Eq. (5) into Eq. (3), the constitutive model to describe the flow stress of individual grain is obtained:

$$
\sigma_{i}\left(m_{i}, N, \varepsilon\right)=\frac{m_{i}}{\bar{m}} \sigma_{0}(\varepsilon)+N k(\varepsilon)
$$

where $\sigma_{i}$ and $m_{i}\left(m_{i} \in[2,3.674]\right)$ are the flow stress and orientation factor of the $i$ th grain in the workpiece, respectively. $\bar{m}$ is the mean orientation factor, which is equal to 3.06. $N$ is the size factor related to $d$ and $t$ of the workpiece. $\sigma_{0}(\varepsilon)$ and $k(\varepsilon)$ are power-law functions, which are described in Eq. (4).

\subsection{FE model for the microforming process}

To validate the proposed constitutive model, FEM was applied to simulate the extrusion operation of microgear forming of two scenarios with different scaling factors and grain sizes, as shown in Fig. 8. The natural-like polycrystalline tessellation was created in FEM model by a controlled Voronoi method [28]. After the generation of polycrystalline structures, each grain needed to be assigned material properties based on its orientation factor $m$ using Abaqus Script. In this study, the orientation factor of each grain was generated in the valid range randomly with a given mean value. The distributions of the orientation factors in these two scenarios are illustrated in Fig. 9 (b, d). It can be found that the distributions are close to the normal distribution with a large number of grains involved in the statistic. In addition, the range of flow stress for all grains involved in the two workpieces are plotted in Fig. 9 (a, c), which presents the different properties among various grains, thus the inhomogeneous microstructures in micro-scaled workpiece can be reflected. In the simulations, the second-ordered CPS3 element was used for meshing to adapt irregular grain shapes and interfaces. The punch and die were rigid body. The strokes of punch were $0.2 \mathrm{~mm}$ for Case 1 and $0.4 \mathrm{~mm}$ for Case 2. The friction coefficient between the die and the sheet was 0.1 . The lateral edges 
of the sheet were set as Y-symmetric. The simulations were conducted in Abaqus/Standard environment.

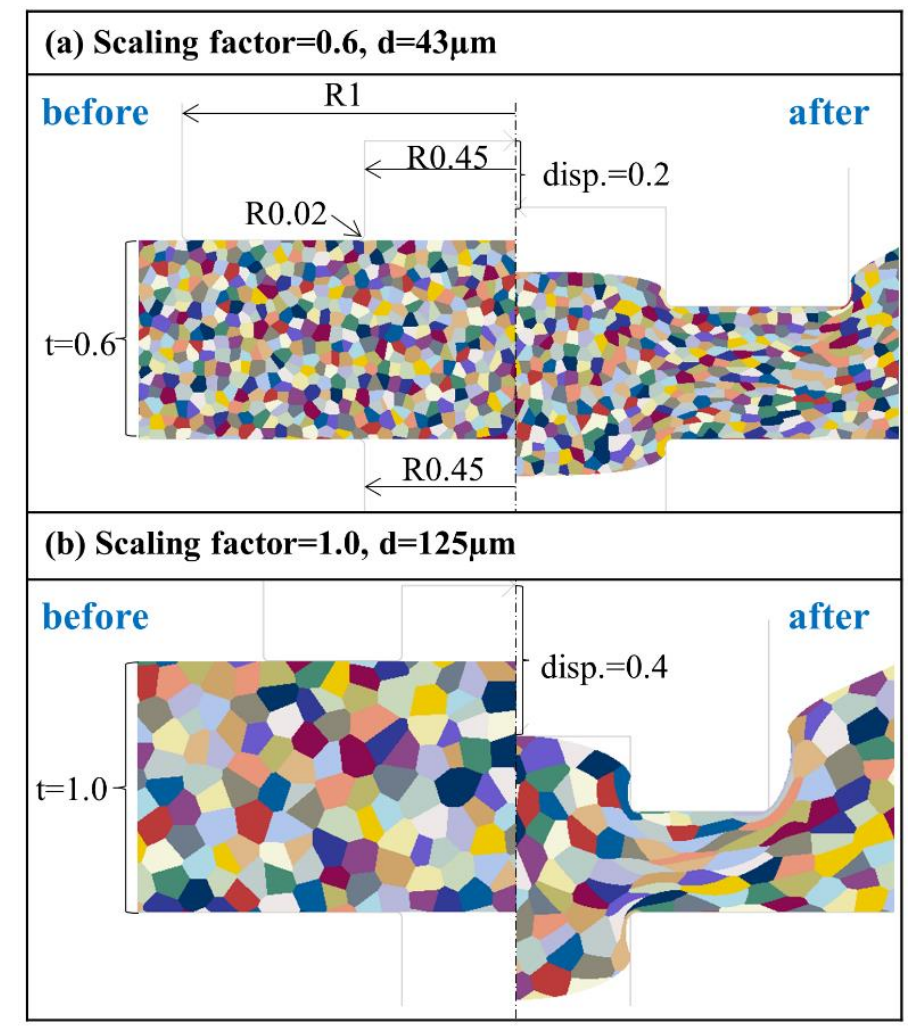

Fig. 8 The FEM models with different scaling factors and grain sizes using for the simulation of the extrusion operation of microgear forming. (a) Case 1: scaling factor is 0.6 and grain size is $43 \mu \mathrm{m}$; (b) Case 2: scaling factor is 1.0 and grain size is $125 \mu \mathrm{m}$. 

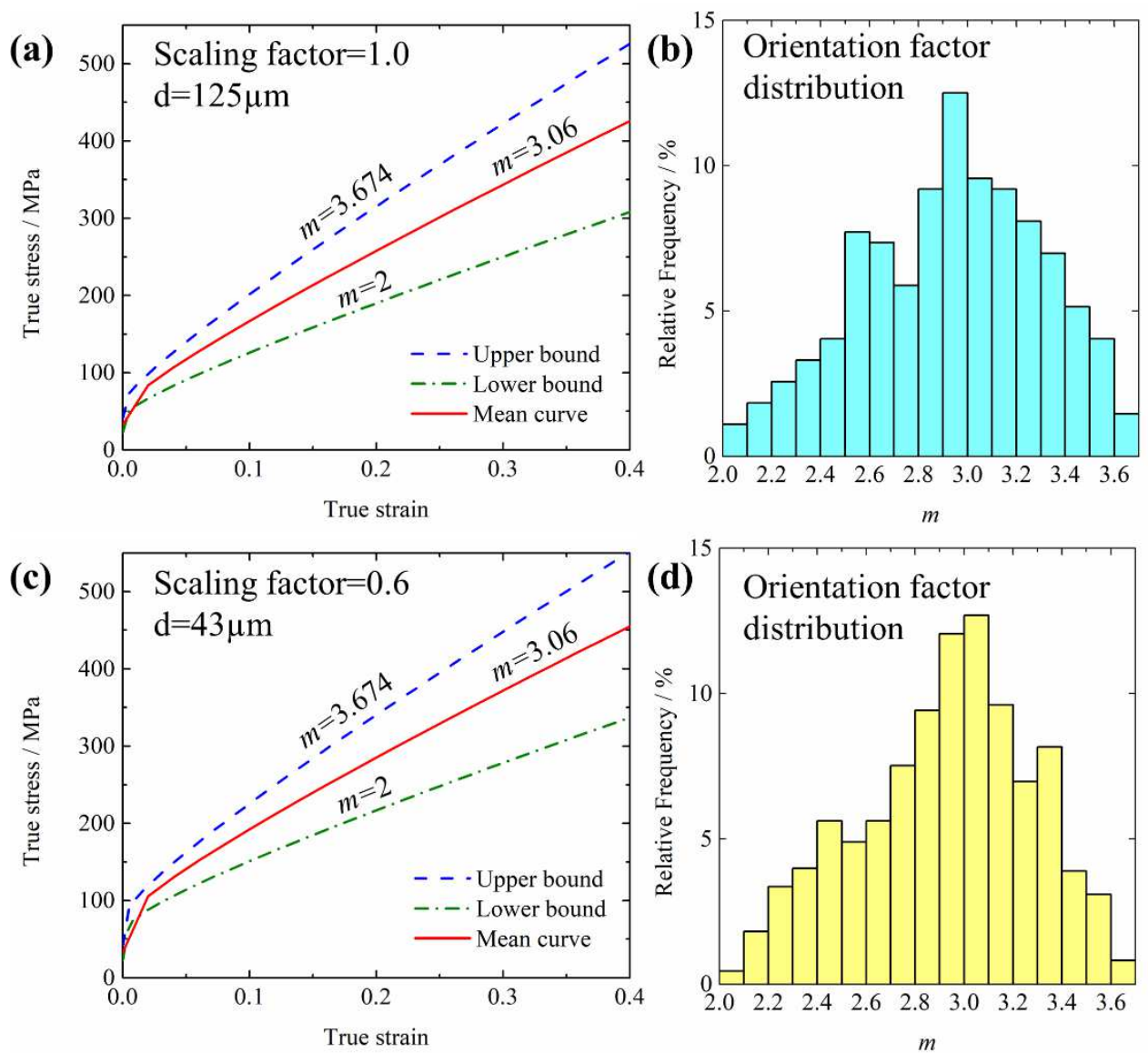

Fig. $9(a, c)$ The range of flow stress and $(b, d)$ the distribution of orientation factors of the two simulation scenarios.

\section{Result and discussion}

\subsection{Deformation load}

The curves of deformation load and stroke in the experiments are shown in Fig. 10. By the comparison between two scaling factors, it is revealed that the deformation load is reduced with the grain size growing, caused by the grain boundary strengthening effect. Dislocations movement could be blocked by the grain boundaries, which results in the hardening of material. When the grains are large, the proportion of grain boundary decreases, thus the hardening effect is weakened a lot. In addition, the comparison of 
the load curves between simulations and experiments is illustrated in Fig. 11. It is found that the simulation curves are little higher than the experimental curves, which could be induced by the difference between the boundary condition and the actual conditions. As shown in Fig. 11 (a), the simulations using the proposed model and the conventional method are conducted with the scaling factor of 1.0 and grain size of $125 \mu \mathrm{m}$. The results of two simulations are very close, which proves the accuracy of the proposed model in the prediction of deformation load.
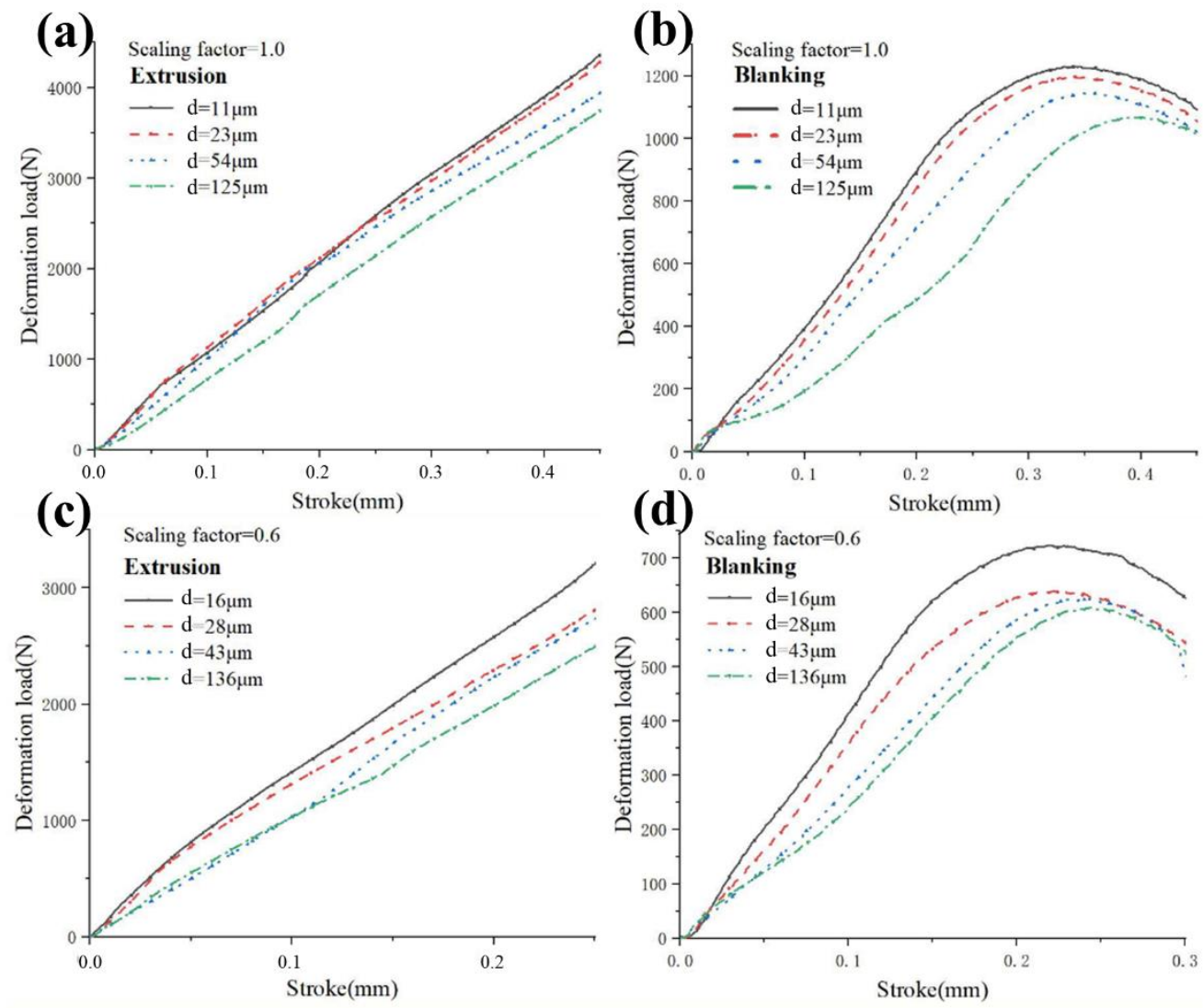

Fig. 10 Deformation load-stroke of the (a) extrusion and (b) blanking operations of microgears with various scaling factors and grain sizes. 

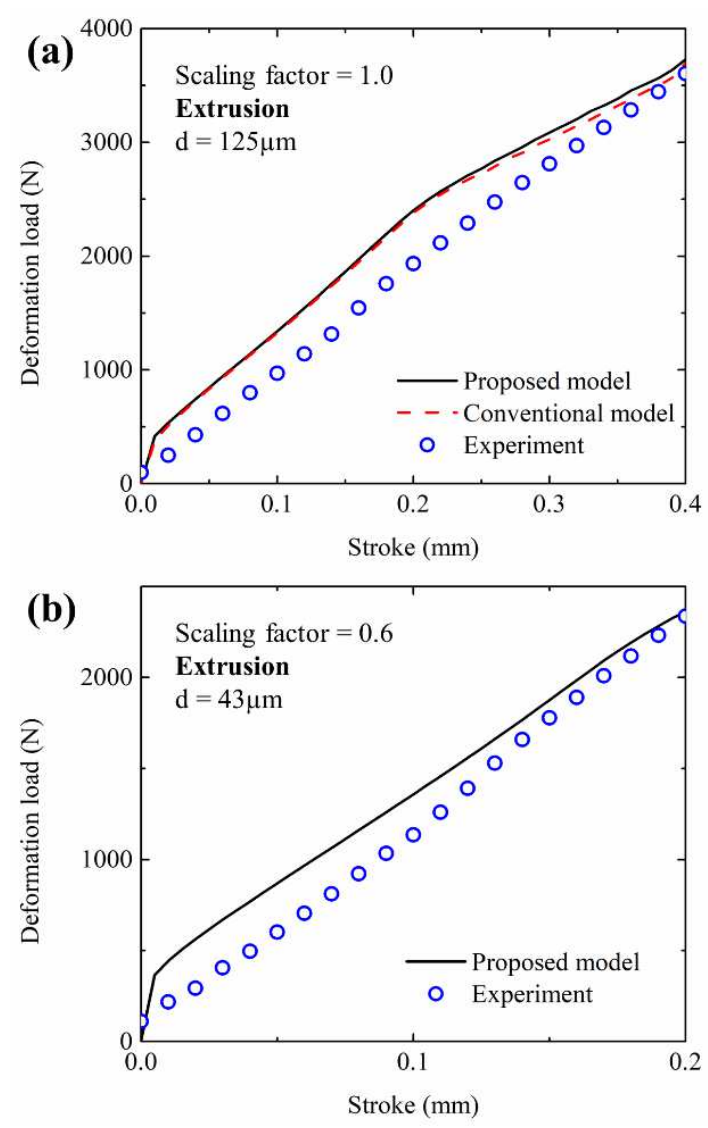

Fig. 11 Comparision of deformation load between experiments and simulations: (a) scaling factor is 1.0 and grain size is $125 \mu \mathrm{m}$; (b) scaling factor is 0.6 and grain size is $43 \mu \mathrm{m}$.

\subsection{Microstructures}

Fig. 12 shows the microstructures on the cross-section of the formed microgears. Five domains on the cross-section of the gear teeth can be identified according to the material flow behaviors. Thus, Zones I to V are illustrated in Fig. 13 (a-d). Zone I is a less deformed area out of the extrusion region. Two dead zones (Zone II, IV) could be found on the cross-section, which have relatively less deformation and almost no material flow. Zones II and IV have a semicircular shape, which gradually becomes larger with grain size increasing due to a smaller number of grains bearing the distortion. The grains within Zone III are obviously elongated and rotated. This zone is located in the middle of gear teeth and gets narrower with the grain size rising. Zone V appears at 
the gear teeth edge due to shearing in the blanking operation, where the grains are seriously deformed. In addition, it can be found that there are grain cracks on the coarsegrained material, as illustrated in Fig. 13 (e, f). Since only a few grains are participating in the deformation, each grain deforms more seriously, resulting in a larger shear angle in single grains, which leads to the occurrence of grain crack.

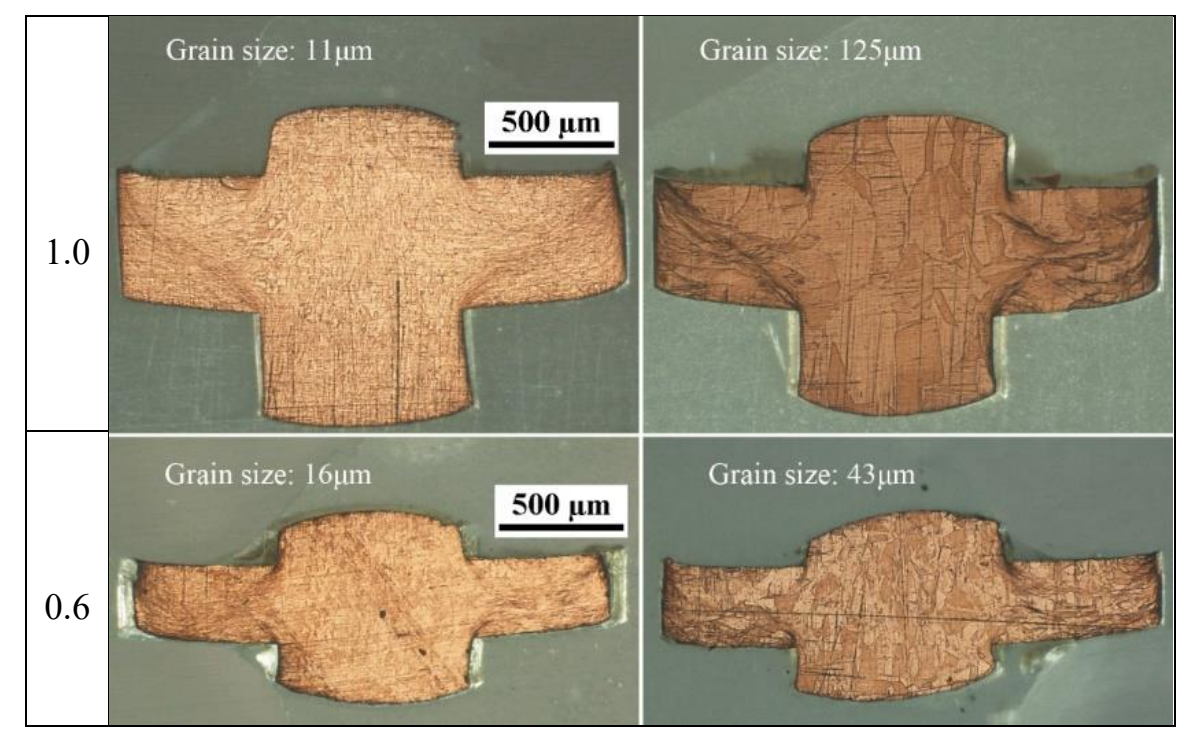

Fig. 12 Microstructures on the cross-sections of the formed gears with various scaling factors and grain sizes. 


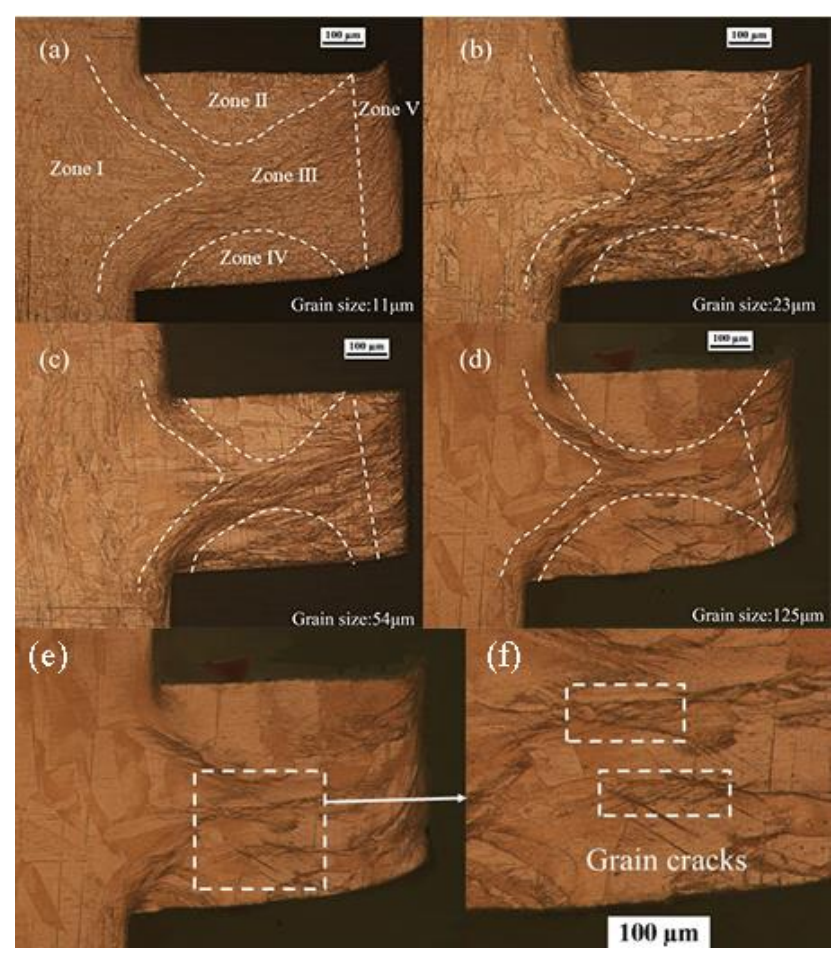

Fig. 13 (a-d) Microstructures of the formed gear teeth with scaling factor of 1.0 and various grain sizes; (e-f) grain cracks on the coarse-grained microstructure.

\subsection{Distribution of stress and strain}

Based on the proposed modeling method, numerical simulations of the extrusion operation were performed and compared with the conventional method. The results of stress and strain distribution are shown in Fig. 14. As shown in the stress results, the distributions on the central undeformed area are similar, but the distributions on the extrusion area are obviously different. The conventional method can only predict an average stress value on the deformed area, but the simulation using the proposed model can obtain an inhomogeneous stress distribution, which is the result of the different mechanical properties among the grains involved in the deformation. There is about $210 \mathrm{MPa}$ deviation between the maximum and minimum values in the extrusion area. This result cannot be obtained by the conventional method. On the other hand, the strain distributions by both methods show generally similarities but local differences. The 
division of shear band from the result of the conventional method is clearly identified, but the simulation using the proposed model shows localized inhomogeneity. Similar results can also be found on the smaller one, as shown in Fig. 15. The distribution is more even due to the increased number of grains involved in deformation.

(a) Proposed model

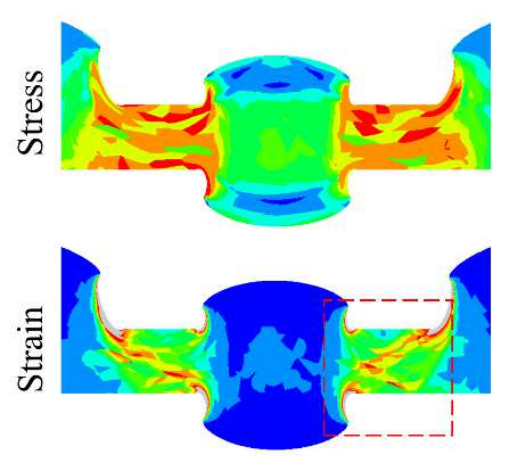

(b) Conventional model

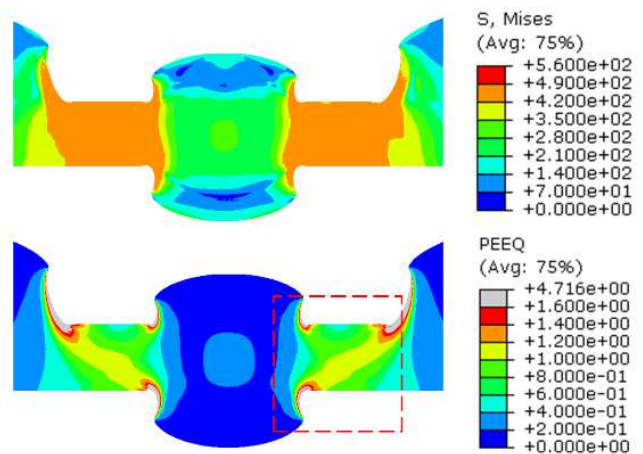

Fig. 14 Distribution of equivalent stress and strain with the scaling factor of 1.0 and grain size of $125 \mu \mathrm{m}$ from the simulation of the extrusion operation using (a) the proposed model and (b) the conventional model.

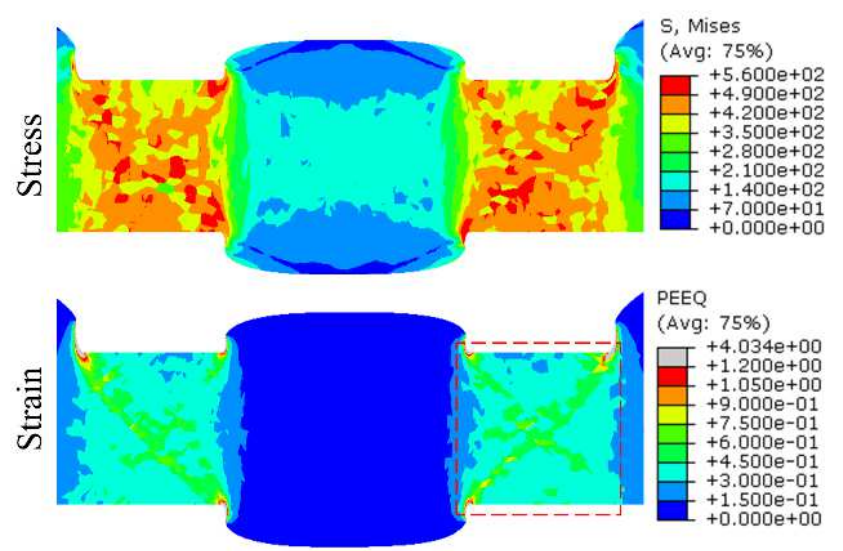

Fig. 15 Distribution of equivalent stress and strain with the scaling factor of 0.6 and grain size of $43 \mu \mathrm{m}$ from the simulation of the extrusion operation using the proposed model.

By comparison with the experimental observation, the deformation domains can be identified from the distribution of strain, as shown in Fig. 16 and 17. Except the blanking-induced Zone $\mathrm{V}$, the other four extrusion-induced zones can be clearly identified on both the simulations using the proposed model and the conventional 
method. For the larger scaled one, as shown in Fig. 16, Zones II and IV are almost symmetrical near the upper and lower edges, but in the simulation results, they are not. However, for the smaller scaled one in Fig. 17, the deformation zones in simulation are different from them in experiments, which could be induced by the hard controlling of stroke in microscale, further resulting in the undesirable microstructural distribution.

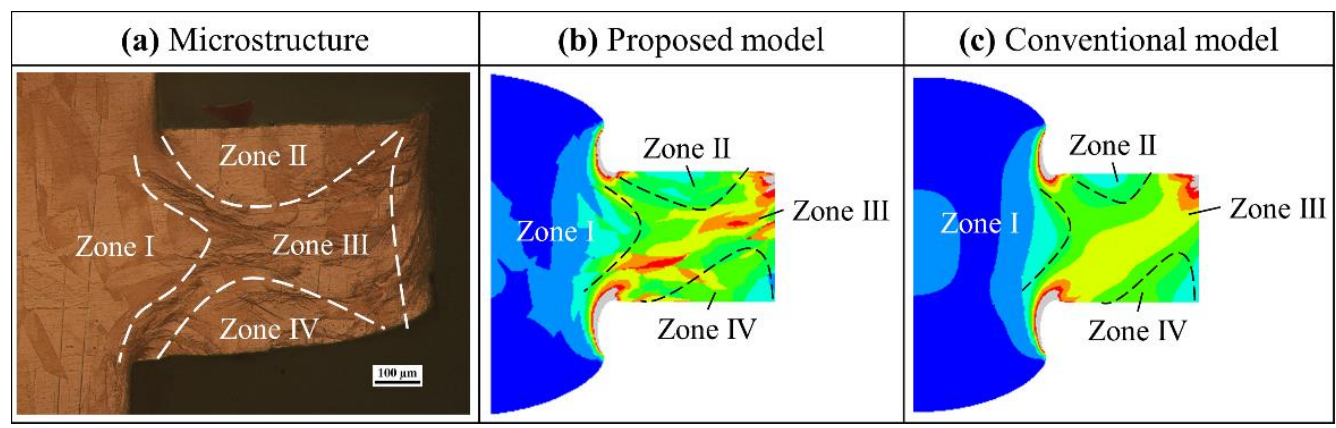

Fig. 16 The deformation zones on the cross-section of (a) experimental observation, (b) simulation using the proposed model, and (c) the conventional simulation with scaling factor of 1.0 and grain size of $125 \mu \mathrm{m}$.

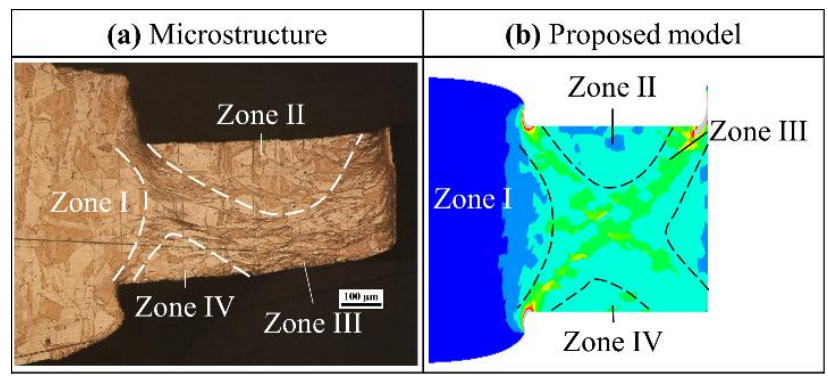

Fig. 17 The deformation zones on the cross-section of (a) experimental observation and (b) simulation using the proposed model with scaling factor of 0.6 and grain size of $43 \mu \mathrm{m}$.

\subsection{Undesirable geometries}

Material unfilling is a common problem in metal forming processes, which can further result in the generation of undesirable geometries, as shown in Fig. 18. For the material unfilling on the shaft end in Fig. 18 (a), the trapped gas is a possible inducement. The pressure of trapped gas increases significantly with the material filling in the closed cavity, which would make the further material compression very hard even 
impossible [29]. Another inducement is the friction between material and die, which makes the outside material flow more slowly than the central material. So, the shaft end of microgear forms the domed shape finally.
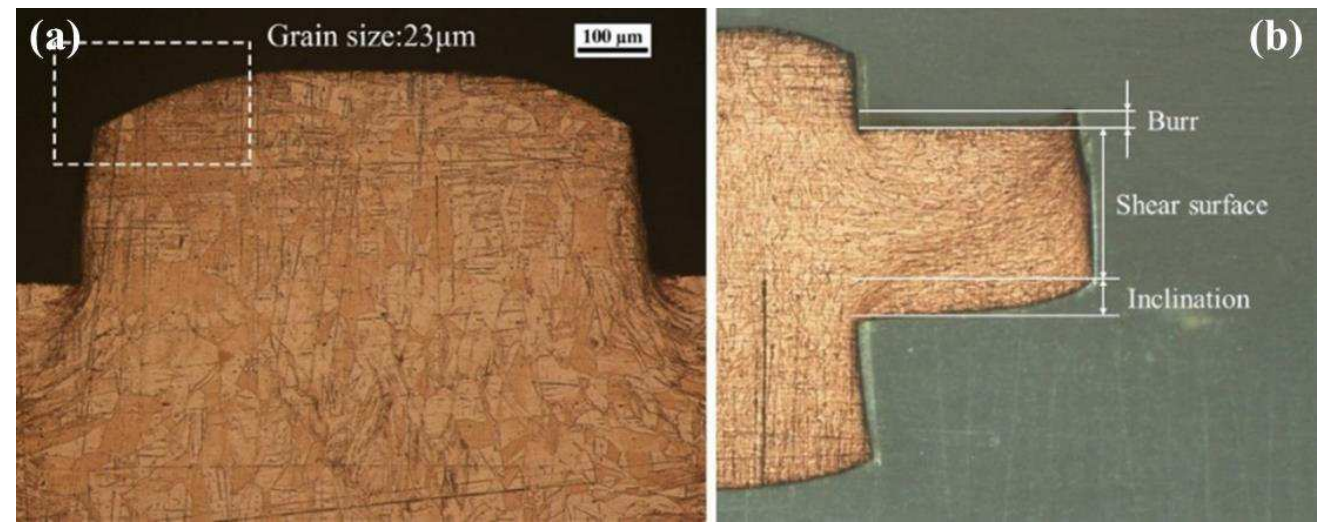

Fig. 18 (a) Material unfilling on the shaft end. (b) The illustration of the undesirable geometries on the gear teeth

As shown in Fig. 18 (b), burr and inclination are inevitably generated in the blanking operation. To quantitatively study the size effect on the formation of these undesirable geometries, their sizes on the formed parts with various material conditions were measured and illustrated in Fig. 19. The length of the burr has no obvious trend with the variation of grain size, since its formation is affected by multifactor such as lubricant, die clearance, original metal material thickness, and grain size simultaneously. The length of inclination grows up with the grain size for two scaling factors, especially for scaling factor 0.6. When there are a bit grains along the sheet thickness direction involved in deformation, the grain boundary strengthening effect is weakened to make the brass sheets easily deform. Therefore, the inclination size rises with the grain size. 

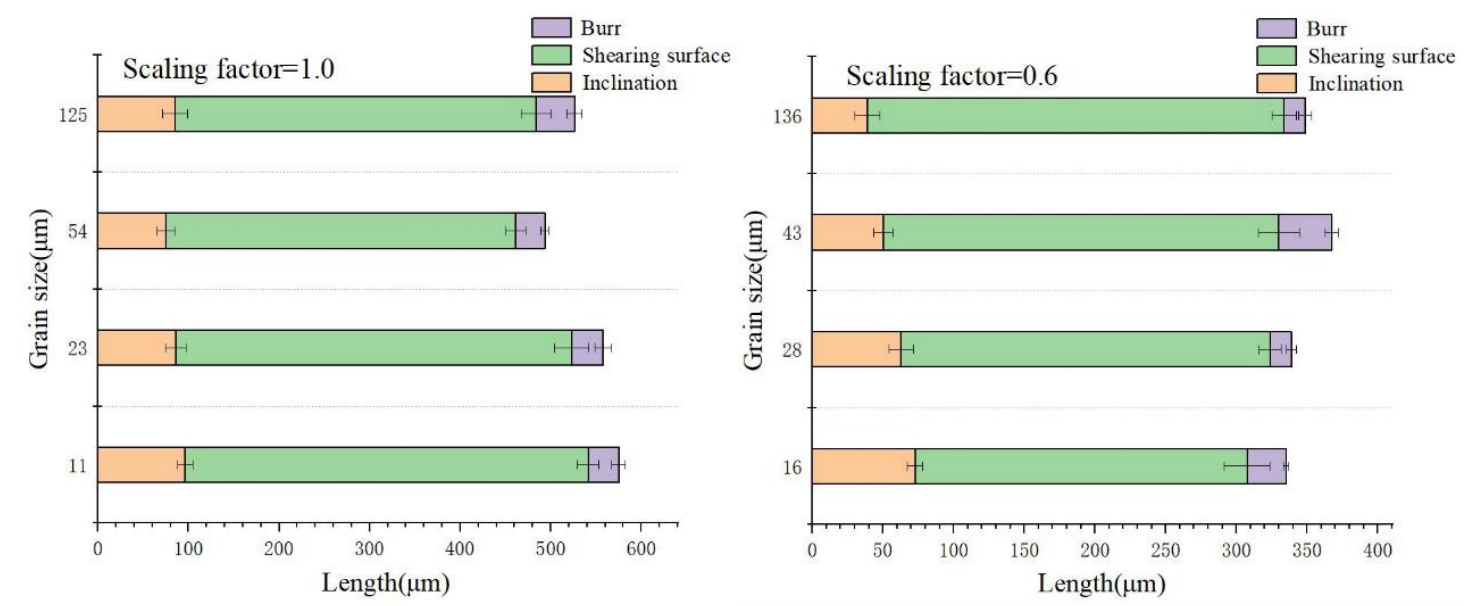

Fig. 19 The sizes of undesirable geometries with different grain sizes of scaling factor 1.0 and 0.6.

\subsection{Microhardness}

Hardness is an important quality index that can determine the service life of parts. Due to the plastic deformation in metal forming, work hardening happens by the initiation and shift of dislocations within the crystal structure [30], which largely increases the hardness of part. To evaluate the hardening behaviors during microforming, the microhardness on the different positions of the final microgears was measured, as shown in Fig. 20. By comparing the hardness of original material and formed parts, the hardness increases significantly after the extrusion and blanking operations, but it varies a lot in different positions due to the different deformation conditions. As shown in Fig. 20 (c-e), the maximum hardness of occurs at position 4 of the formed part. The most serious material flow occurs at this domain, resulting in the highest hardness. The hardness at positions 2 and 6 is the second highest, where the material flows through to form two shaft features, thus grains in this area undergo serious plastic deformation. The distribution of high hardness positions conforms to the formation of Zone III in Section 4.2. On the other hand, positions 1 and 7 have the lowest hardness, which indicates less material flow at these areas, and they locate at the two dead zones (Zone II, IV). For the same scaling factor, the hardness on the same 
position decreases obviously with the growth of grain size, as illustrated in Fig. 20 (d, e), which can be explained by the decreasing grain boundary strengthening effect.
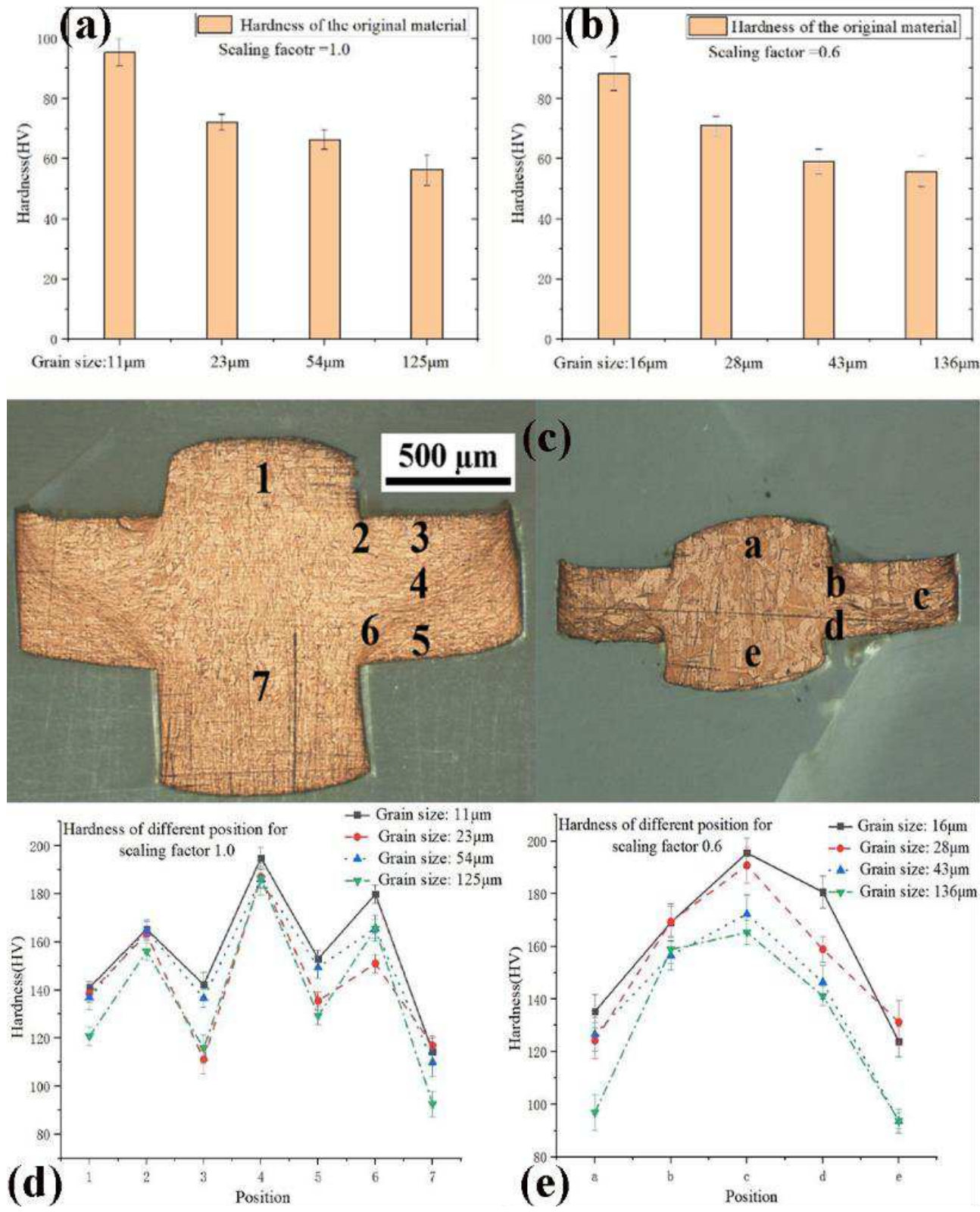

Fig. 20 (a, b) Microhardness of the two size-scaled original materials. (c) The position of hardness test on the cross-section of the formed microgears. $(\mathrm{d}, \mathrm{e})$ Microhardness of the microgears with two scaling factors and various grain sizes. 


\subsection{Surface quality}

The surface morphology was observed by Scanning Electron Microscope (SEM) to study the surface forming quality of microgears. As shown in Fig. 21, the main surface defects include bulge, fracture, micropits, burr, voids, and uneven surface. The fracture resulting from microvoid growth and nucleation occurs at the edge of gear teeth during the blanking operation. The grain size effect on the quality of blanking surface is illustrated in Fig. 22. For the scaling factor of 1.0, the surface quality of gear teeth does not change greatly when the grain size varies. For the scaling factor of 0.6 , however, the surface quality of gear teeth is worsened obviously with grain size increasing. When grains are larger, there are fewer numbers and a more random distribution of grains. Anisotropic single grain prefers to deform in a specific direction, making the whole deformation process more inhomogeneous.

To analyze the size effect on surface quality quantitively, the surface roughness of the gear teeth with different grain sizes was measured, and the results are illustrated in Fig. 23. It can be found that for the scaling factor of 0.6 the roughness grows up obviously with grain size increasing, which means the surface quality is worsened. For the scaling factor of 1.0, however, the roughness fluctuates in a limited range, which means grain size has a limited effect on the surface quality when the size scale increases. 


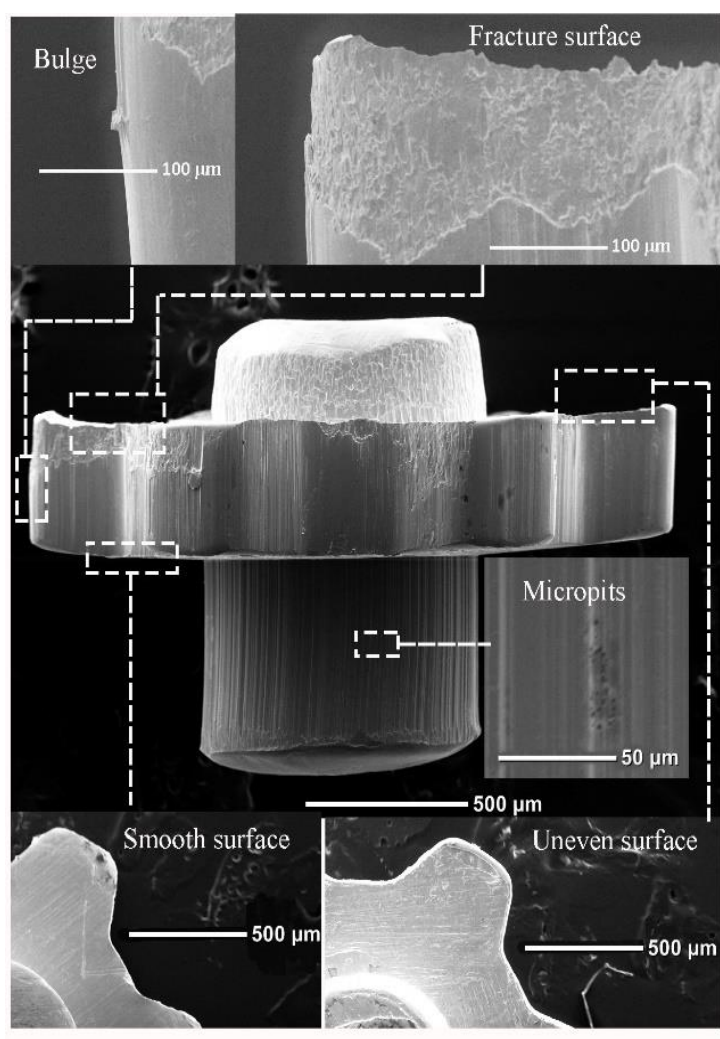

(a)

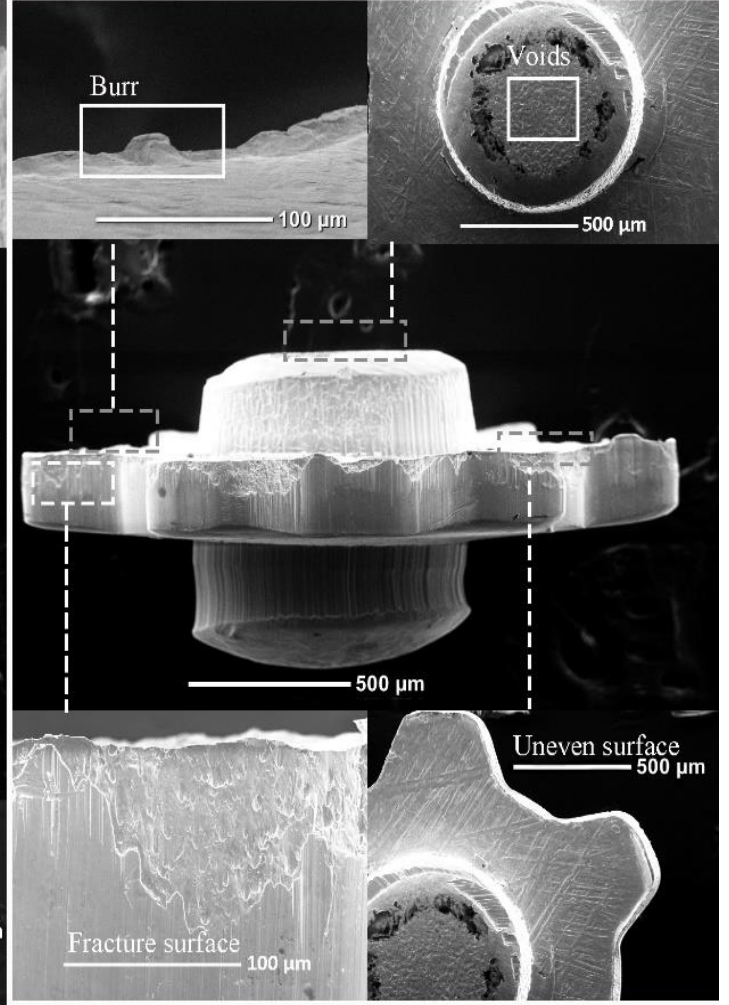

(b)

Fig. 21 The surface defects on the microgear surface: (a) scaling factor 1.0, grain size $125 \mu \mathrm{m}$; (b) scaling factor 0.6 , grain size $28 \mu \mathrm{m}$.
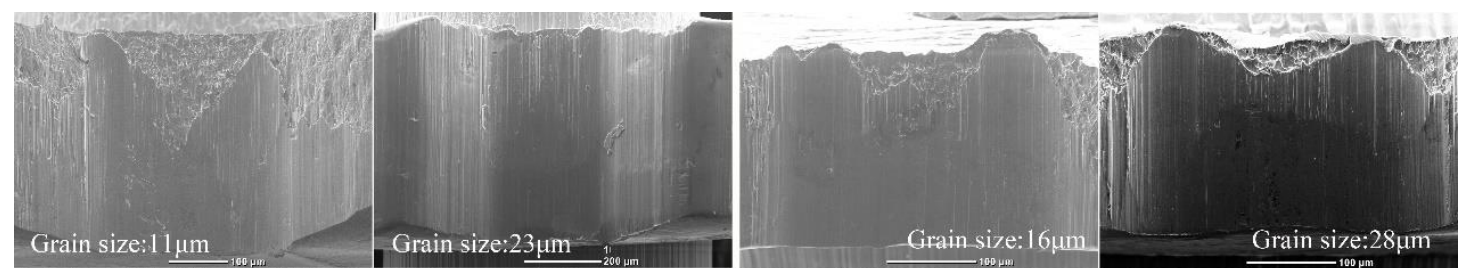

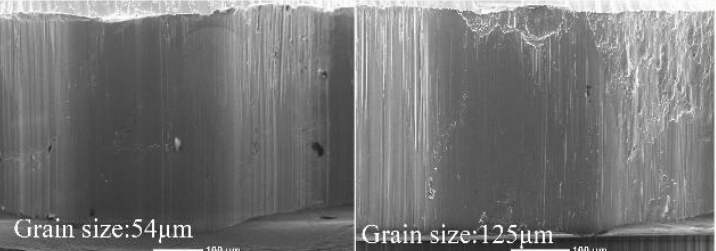

(a) Scaling factor 1.0

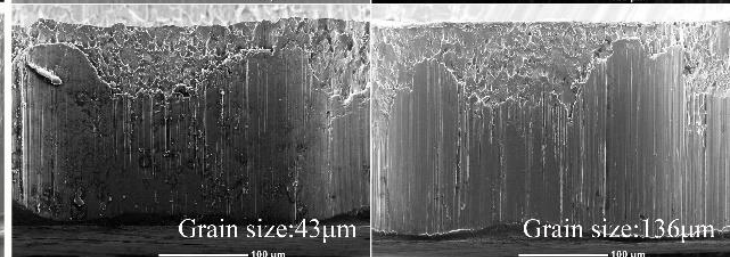

(b) Scaling factor 0.6

Fig. 22 The side surface of the gear teeth with different grain sizes for the scaling factor of (a) 1.0 and (b) 0.6. 


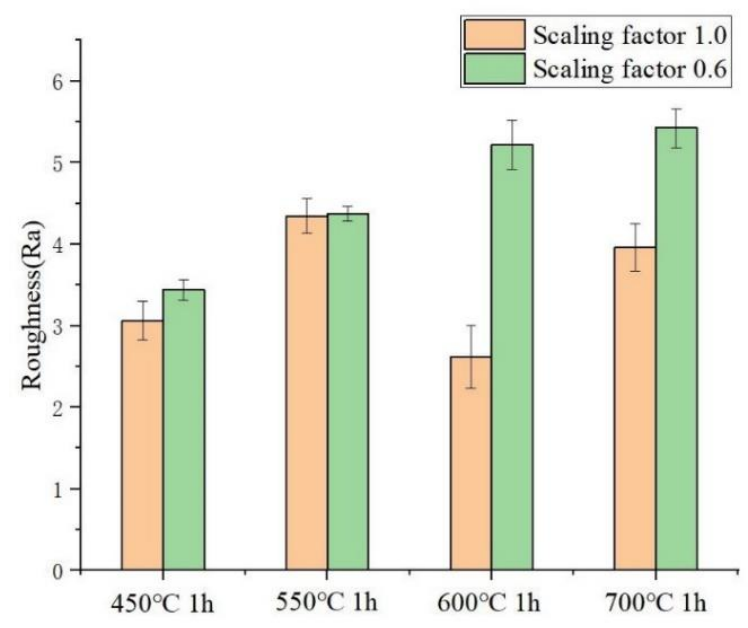

Fig. 23 The surface roughness on the side surface of gear teeth.

\section{Improvement of the microforming system}

\subsection{Quality problems of microgears}

The inclination defect is caused directly by the blanking operation, which could be resulted from the interactive influences of grain size, die constraint, and fracture [31]. For the inclination on gear teeth in this study, the lack of die constraint is a major reason causing this undesirable geometry. To get desirable geometries of teeth, a constraint die contacted with the bottom surface should be adopted. As the results in the above sections, the inclination increases with the growth of grain size.

On the other hand, the punch for forming the upper shaft in the microforming system has a closed cavity, the trapped air in the closed die cavity is continuously squeezed in the forming process, thus its pressure increases with the continuous filling of material in the extrusion operation. When the air pressure in the closed die cavity is increased to a certain value that equals the sum of the punch pressure and the atmospheric pressure, the material will no longer be filled into the die cavity, which results in the domed shape of the upper shaft of microgear. 


\subsection{Improved design of tooling}

Considering the industrial application of microgears, the inclination of gear teeth and material unfilling of the shaft are serious problems. According to the above analysis, tooling redesign is one of the efficient ways to solve these problems, and the improved design of the microforming system is illustrated in Fig. 24. Marked by the red dashed boxes in Fig. 24 (a), the original holed punch was changed to the punch pin with a sleeve, so the fit clearance can be used for venting during extrusion to avoid air pressure rising. Hence, the material unfilling can be improved. On the other hand, to avoid the inclination of the gear teeth, a die insert was added into the original die of the blanking operation, which acted as the constraint to the bottom surface of teeth and shaft, as shown in Fig. 24 (b). In this case, a slight forging was performed after blanking, which can adjust the undesirable inclination to the desired shape to some extent.
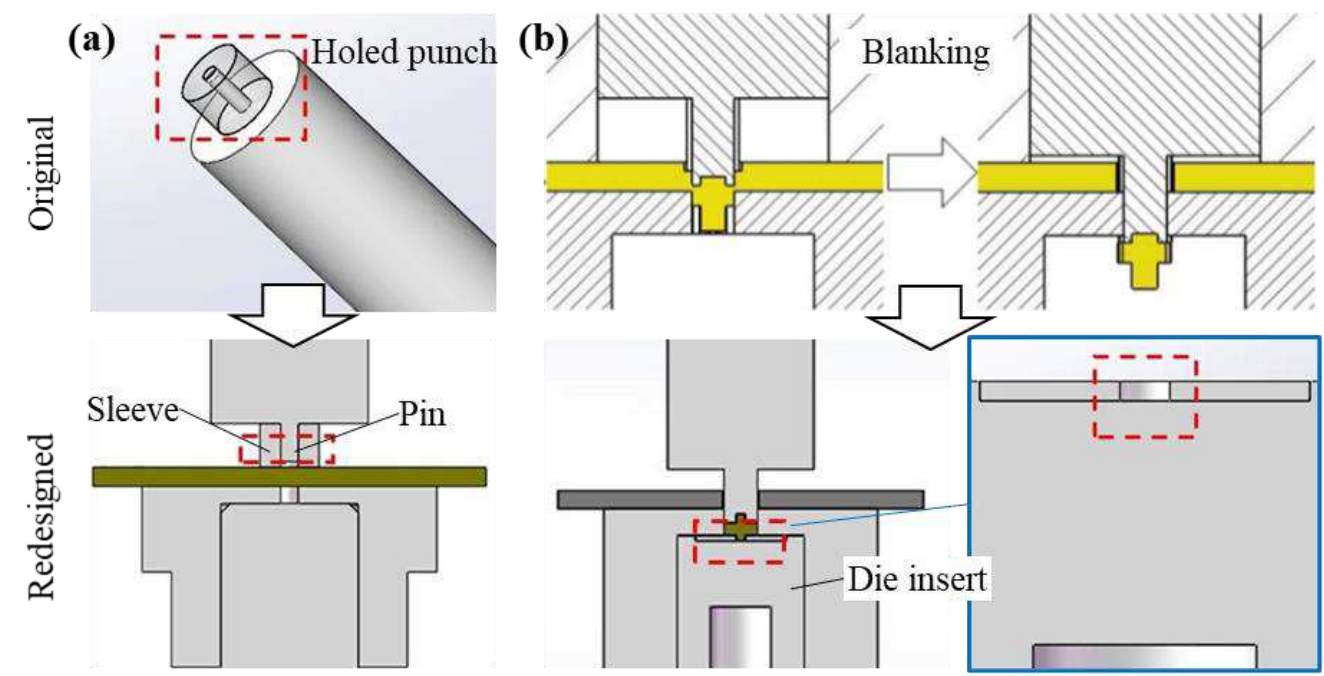

Fig. 24 The original and redesigned microforming system: (a) the extrusion operation; (b) the blanking operation.

The improved forming process of the redesigned system is shown in Fig. 25 (a). In the first operation namely extrusion, the gear shafts on two sides are formed first. Then the brass sheet was moved along the feed direction by a certain distance after the release 
of blank holder. In the second operation namely blanking, the formed shafts are used for positioning, the gear teeth are cut off from the brass sheet by shearing. With the punch moving down, an additional forging is performed with the constraints of the die insert, and the inclination formed in blanking can be improved.

The microstructures of the microgears before and after redesigning are illustrated in Fig. 25 (b) to show the differences obviously. It is found that the gear teeth inclination is improved visibly for both scales. Moreover, the material filling of the gear shafts becomes more sufficient, but unfilling still exists due to the interfacial friction. Therefore, the improved design can effectively solve the problems of inclination and material unfilling in the progressive forming of microgears.

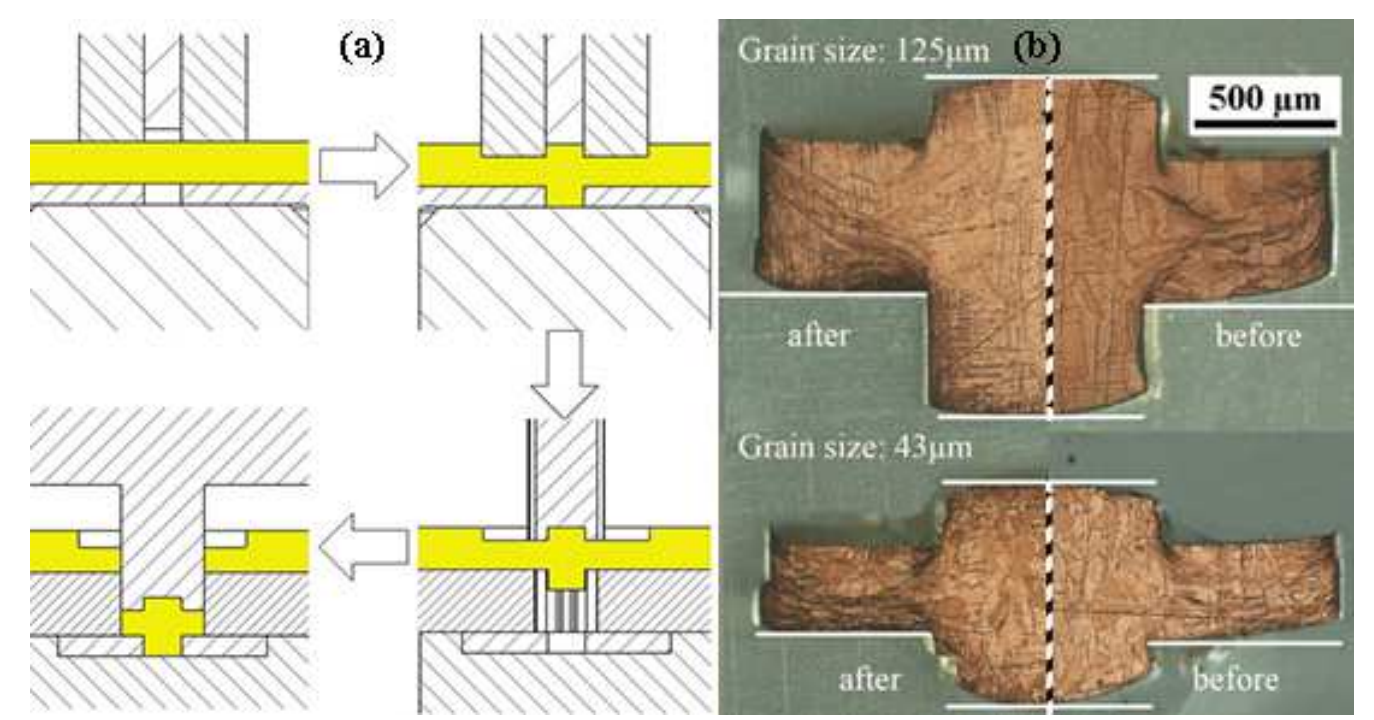

Fig. 25 (a) The forming process of the redesigned forming system. (b) Comparison of the formed gears before and after redesigning.

\section{Conclusions}

Two scaled shafted gears with various grain sizes were manufactured by progressive forming, and the fabricated part and microforming process were analyzed in terms of deformation load, microstructures, undesirable geometries, microhardness, 
and surface quality. A size-dependent model was proposed and applied in FEM simulation of the whole process to reveal the deformation behaviors of the forming process. Based on the forming problems, the forming system was redesigned, which can fabricate microgears with better quality. The following conclusions are drawn:

(1) The deformation load is decreased with the increase of grain size, and the simulation using the proposed model can accurately predict the deformation load.

(2) Five zones of the microstructure in the final parts are identified, and their areas vary with grain size and scaling factor. The zones have the characteristic stress and strain distributions and different hardness reflecting the extent of deformation. The simulation using the proposed model can predict the formation of these zones and the inhomogeneous deformation during forming process.

(3) Material unfilling of the shaft and the inclination of the gear teeth are two undesirable geometries of the microformed gears. The inclination gets worsened with the larger grains. The microforming system was redesigned to solve these problems, and the new fabricated parts have obviously better forming quality than before. In addition, the side surface of the teeth has poor quality and deteriorates with the increase of grain size and the small scaling factor.

\section{Acknowledgments}

The authors would like to acknowledge the funding support to this research from the projects of ZE1W and BBAT from The Hong Kong Polytechnic University and the National Natural Science Foundation of China (NSFC) key project of No. 51835011. 


\title{
Statements and declarations
}

\author{
Competing interests
}

The authors declare no competing interests.

\section{References}

[1] Geiger M, Kleiner M, Eckstein R, Tiesler N, Engel U (2001) Microforming. CIRP Annals 50(2): 445-462. 10.1016/s0007-8506(07)62991-6

[2] Fu MW, Wang JL (2021) Size effects in multi-scale materials processing and manufacturing. Int J Mach Tool Manu 167: 103755. https://doi.org/10.1016/j.ijmachtools.2021.103755

[3] Ngo TD, Kashani A, Imbalzano G, Nguyen KTQ, Hui D (2018) Additive manufacturing (3D printing): A review of materials, methods, applications and $\begin{array}{lllll}\text { challenges. } & \text { Compos } & \text { B } & \text { Eng } & 143 \text { : }\end{array}$ https://doi.org/10.1016/j.compositesb.2018.02.012

[4] Joe H-E, Kang E-G, Martin B (2018) A Review of State of the Art of Electron Beam and Ion Beam Machining. J Korean Soc Precis Eng 35(3): 241-252.

[5] Geng X, Chi G, Wang Y, Wang Z (2014) Study on Microrotating Structure Using Microwire Electrical Discharge Machining. Materials and Manufacturing Processes 29(3): 274-280. 10.1080/10426914.2013.864398

[6] Faisal N, Zindani D, Kumar K, Bhowmik S, Laser Micromachining of Engineering Materials-A Review, in: K. Kumar, D. Zindani, N. Kumari, J.P. Davim (Eds.), Micro and Nano Machining of Engineering Materials: Recent Developments, Springer International Publishing, Cham, 2019, pp. 121-136.

[7] Yuan J, Lyu B, Hang W, Deng Q (2017) Review on the progress of ultra-precision machining technologies. Frontiers of Mechanical Engineering 12(2): 158-180. 10.1007/s11465-017-0455-9

[8] Engel U, Eckstein R (2002) Microforming_from basic research to its realization. 
Journal of Materials Processing Technology 125: 35-44.

[9] Cao J, Brinksmeier E, Fu M, Gao RX, Liang B, Merklein M, Schmidt M, Yanagimoto J (2019) Manufacturing of advanced smart tooling for metal forming. CIRP Ann 68(2): 605-628. 10.1016/j.cirp.2019.05.001

[10] Ghassemali E, Tan M-J, Jarfors AE, Lim S (2013) Progressive microforming process: towards the mass production of micro-parts using sheet metal. The International Journal of Advanced Manufacturing Technology 66(5-8): 611-621.

[11] Zheng JY, Yang HP, Fu MW, Ng C (2019) Study on size effect affected progressive microforming of conical flanged parts directly using sheet metals. J Mater Process Tech 272: 72-86. https://doi.org/10.1016/j.jmatprotec.2019.05.007

[12] Zheng J-Y, Wang J, Fu MW (2021) Experimental and numerical study of the size effect on compound Meso/Microforming behaviors and performances for making bulk parts by directly using sheet metals. J Manuf Process 66: 506-520. https://doi.org/10.1016/j.jmapro.2021.04.037

[13] Zheng J-Y, Shi SQ, Fu MW (2020) Progressive microforming of pin-shaped plunger parts and the grain size effect on its forming quality. Mater Design 187: 108386. https://doi.org/10.1016/j.matdes.2019.108386

[14] Chan WL, Fu MW, Lu J, Liu JG (2010) Modeling of grain size effect on micro deformation behavior in micro-forming of pure copper. Mater Sci Eng A 527(24): 66386648. https://doi.org/10.1016/j.msea.2010.07.009

[15] Chan WL, Fu MW (2012) Experimental and simulation based study on microscaled sheet metal deformation behavior in microembossing process. Mat Sci Eng aStruct 556: 60-67. 10.1016/j.msea.2012.06.058

[16] Wang JL, Fu MW, Shi SQ (2017) Influences of size effect and stress condition on ductile fracture behavior in micro-scaled plastic deformation. Materials \& Design 131: 69-80. 10.1016/j.matdes.2017.06.003

[17] Choudhury IA, Shirley S (2010) Laser cutting of polymeric materials: An experimental investigation. Optics \& Laser Technology 42(3): 503-508. 10.1016/j.optlastec.2009.09.006

[18] Chen C-C (2015) Grain-size effect on the forging formability of mini gears. Int J Adv Manuf Tech 79(5-8): 863-871. 10.1007/s00170-015-6883-y 
[19] Debin S, Jie X, Chunju W, Bin G (2008) Hybrid forging processes of micro-double gear using micro-forming technology. The International Journal of Advanced Manufacturing Technology 44(3-4): 238-243. 10.1007/s00170-008-1829-2

[20] Tay BY, Loh NH, Tor SB, Ng FL, Fu G, Lu XH (2009) Characterisation of micro gears produced by micro powder injection moulding. Powder Technology 188(3): 179182. 10.1016/j.powtec.2008.04.047

[21] Liu L, Ni XL, Yin HQ, Qu XH (2015) Mouldability of various zirconia micro gears in micro powder injection moulding. Journal of the European Ceramic Society 35(1): 171-177. 10.1016/j.jeurceramsoc.2014.07.027

[22] Dong X, Chen F, Chen S, Liu Y, Huang Z, Chen H, Feng S, Zhao L, Wu Z, Zhang $X$ (2015) Microstructure and microhardness of hot extruded 7075 aluminum alloy micro-gear. J Mater Process Tech 219: 199-208. 10.1016/j.jmatprotec.2014.12.022

[23] Li J, Liu H, Shen Z, Qian Q, Zhang H, Wang X (2016) Formability of micro-gears fabrication in laser dynamic flexible punching. J Mater Process Tech 234: 131-142. 10.1016/j.jmatprotec.2016.03.018

[24] Vollertsen F, Asghari Ganji A, Bakhshi-Jooybari M, Gorji H, Dean TA, Qin Y, Yuan SJ (2018) Forming of micro gears by compressing a pure copper sheet through its thickness. MATEC Web of Conferences 190. 10.1051/matecconf/201819010004

[25] Wang Y, Chen X, Wang Z, Dong S (2018) Fabrication of micro gear with intact tooth profile by micro wire electrical discharge machining. Journal of Materials Processing Technology 252: 137-147. 10.1016/j.jmatprotec.2017.09.002

[26] Nabarro FRN (1966) Extended dislocations and the schmid law of resolved shear stress. Philos Mag 14(130): 861-866. 10.1080/14786436608211978

[27] Peng L, Lai X, Lee H-J, Song J-H, Ni J (2009) Analysis of micro/mesoscale sheet forming process with uniform size dependent material constitutive model. Mater Sci Eng A 526(1-2): 93-99. 10.1016/j.msea.2009.06.061

[28] Zhang P, Karimpour M, Balint D, Lin J, Farrugia D (2012) A controlled Poisson Voronoi tessellation for grain and cohesive boundary generation applied to crystal $\begin{array}{lllll}\text { plasticity analysis. } & \text { Comput } & \text { Sater } & \text { Sci }\end{array}$ https://doi.org/10.1016/j.commatsci.2012.02.022

[29] Wang JL, Fu MW, Ran JQ (2014) Analysis of size effect on flow-induced defect 
in micro-scaled forming process. The International Journal of Advanced Manufacturing Technology 73(9-12): 1475-1484. 10.1007/s00170-014-5947-8

[30] Fu M, Chan WL (2013) A review on the state-of-the-art microforming technologies. The International Journal of Advanced Manufacturing Technology 67(9-12): 24112437.

[31] Meng B, Fu MW, Fu CM, Chen KS (2015) Ductile fracture and deformation behavior in progressive microforming. Mater Design 83: 14-25. 10.1016/j.matdes.2015.05.088 